\title{
Proyecto de recuperación del Reg Major de l'Alfäs y Benidorm (l'Alfàs del Pi, Alicante)
}

\author{
Carolina Frías Castillejo \\ Ayuntamiento de l'Alfàs del Pi \\ cfrias@lalfas.com
}

\begin{abstract}
Resumen. El Reg Major de l'Alfàs y Benidorm es un regadío histórico cuya construcción se remonta a mediados del siglo XVII y que recorre las tierras de Polop, la Nucia, l'Alfàs del Pi y Benidorm, en la provincia de Alicante. En esta comunicación presentamos una propuesta de recuperación del sistema de riego histórico a su paso por l'Alfàs del Pi. La filosofía del proyecto se basa en interrelacionar tres ejes: patrimonio, paisaje y agua a partir de una perspectiva que integre diferentes visiones sectoriales en un mismo entorno territorial. Se trata de poner en valor un paisaje histórico, un paisaje cultural entendido como cualquier parte del territorio cuyo carácter sea el resultado de la acción y la interacción de factores naturales humanos. Esta huella de la acción humana en el paisaje iniciada en 1666 ha marcado la evolución posterior de la comarca de la Marina Baixa. La identidad de estas poblaciones tiene su origen en este paisaje del agua, por lo que consideramos imprescindible acometer su conservación y divulgación para preservar y transmitir un patrimonio etnológico de primer orden que se encuentra en peligro de desaparecer.
\end{abstract}

Palabras clave: riego histórico, paisaje cultural, intervención integral.

\begin{abstract}
The "Reg Major de l'Alfàs y Benidorm" is an historical irrigation system that dates back to the mid 17th century and that crosses through the lands of Polop, la Nucia, l'Alfàs del Pi and Benidorm, located in the province of Alicante. We present a proposal to recover the historical irrigation system as it passes through l'Álfàs del Pi. The idea of the project is based on the interrelation between three axes: heritage, landscape and water, from a perspective that unites different sectorial viewpoints into one same territorial environment. It is a question of valuing an historical landscape, understood as part of a territory with a character that stems from the work and interaction of natural human factors. The print of human activities upon the landscape, which began back in 1666, has guided the later evolution of the Marina Baixa area. The identity of these towns goes back to this landscape of water, therefore we consider essential its conservation and exposure so as to preserve and transmit the first class ethnological heritage that is now threatened with disappearing.
\end{abstract}

Keywords: Historical irrigation system, cultural landscape, comprehensive intervention.

\section{Introducción}

El origen del municipio de l'Alfàs del Pi se encuentra en el Reg Major ${ }^{1}$, un regadío histórico cuya construcción se remonta al siglo XVII. El topónimo de origen árabe Alfas (tierra fértil o tierra cultivada) indica que esta población hunde sus raíces en la cultura del agua, en una forma especial de entender la agricultura, el agua y el paisaje. El Reg Major con sus acequias, acueductos y molinos, con los topónimos, las tradiciones y los regantes conforma el elemento etnológico más significativo de l'Alfàs del Pi.

\footnotetext{
${ }^{1}$ La denominación oficial es Reg Major de l'Alfàs del Pi y Benidorm, según las ordenanzas publicadas en 1927. Desde su creación ha recibido varios nombres, como Nou Reg o Riego Mayor del Alfaz. En este artículo nos referiremos al riego de manera genérica como Reg Major.
} 
La finalidad de este proyecto es llevar a cabo la puesta en valor y dinamización del Reg Major de l'Alfàs atendiendo a sus valores culturales, paisajísticos y naturales. Su intencionalidad se justifica por la necesidad de conservar y recuperar no sólo las estructuras hidráulicas, sino también el territorio y el patrimonio inmaterial asociado al regadío. Por tanto, la filosofía de estainiciativa se basa en interrelacionar tres ejes: patrimonio, paisaje y agua, poniendo en valor un paisaje cultural entendido como cualquier parte del territorio tal como la percibe la población, cuyo carácter sea el resultado de la acción y la interacción de factores naturales y/ o bumanos ${ }^{2}$.

\section{Análisis histórico}

\subsection{El Reg Major y la Baronía de Polop}

Desde la conquista cristiana de las tierras valencianas, l'Alfàs del Pi y casi toda la comarca de la Marina Baixa quedaron integrados en las propiedades de Bernat de Sarrià, un noble catalán que desde finales del siglo XIII fue incrementando su patrimonio mediante la adquisición de señoríos con los beneficios obtenidos en las campañas militares de Jaume II. La consolidación de esta familia como señores territoriales se produjo a partir de 1293, cuando fue adquiriendo los castillos de Callosa, Altea, Polop y demás asentamientos de la actual comarca de la Marina Baixa que conformaron las denominadas Muntanyes d'En Sarriàt. Con el fin de aumentar la presencia de gentes cristianas y de incrementar la percepción de sus rentas Bernat de Sarrià fundó dos nuevas poblaciones: Villajoyosa en $1300 \mathrm{y}$ Benidorm en 1325. Sin embargo, la escasez de agua y los constantes ataques de piratas provocaron el fracaso del asentamiento de población en Benidorm.

A partir del primer tercio del siglo XV la casa Mendoza era dueña de los señoríos de Polop y Benidorm. El miembro de esta familia que más nos interesa es una mujer, Beatriu Fajardo de Mendoza (1619-1678), baronesa de Polop entre 1654 y 1678, quien promovió la construcción del Reg Major. Su motivación para construir el riego no era otra que aumentar la producción de unas tierras de secano y obtener así un mayor provecho de sus rentas. El 1 de abril de 1666 se reunió en el Castillo de Polop en concejo general una representación de los vecinos de Polop, Xirles, la Nucía y Benidorm. Esta reunión, de la que existe una copia posterior del acta redactada en Villajoyosa ${ }^{5}$, marca la puesta en marcha del riego ya que se indica a los vecinos "los cuales puestos y congregados en forma de consejo general, hacen y representan la mayor parte de la Villa y Baronía de Polop" " las condiciones en las que se establece el nuevo riego, con los derechos y obligaciones de los vasallos consignados en 17 capítulos. Pocos días después, el 8 de abril, se otorgó la segunda Carta Pobla de Benidorm.

\footnotetext{
2 Definición de paisaje del Convenio Europeo del Paisaje (Consejo de Europa, Florencia 2000)

${ }^{3}$ Sobre la figura de Bernat de Sarrià se pueden consultar los trabajos de P.M. Orts(1976, 2006b) y Alemany et al.(1988).

4 El gran señorío que el almirante logró fundar en el sur del Reino de Valencia incluía las poblaciones de Confrides, Callosa, Orxeta, Castell de Castells, Polop, Finestrat, Relleu, Benidorm, Altea, Calpe, Benissa, Teulada, Guadalest, Tàrbena, Vall de Pop, Xalò, Gata, Berniça, Murla y la Vall d’Aiora entre otras. P.M. Orts, (2006b, p. 240).

5 Este documento se encuentra depositado en el archivo del Sindicato del Reg Major de l'Alfàs, actualmente con sede en La Nucia.

6 En el acta de la reunión se hace una relación de los 65 asistentes. Muchos de estos apellidos todavía están presentes entre las generaciones de regantes de l'Alfàs. Vid. J.R. Frías $(2008,109)$.
} 
Las obras comenzaron en 1659 y participaron los campesinos de manera gratuita, con un nivel de voluntariado cuestionable dada la obligatoriedad de los vasallos en hacer trabajos para los señores. La obra fue dirigida por el arquitecto Francisco Serrano e implicó la construcción de complejas obras de ingeniería como acueductos y galerías con el fin de salvar los accidentes geográficos existentes y de dotar a la acequia principal de la pendiente adecuada para su correcto funcionamiento.

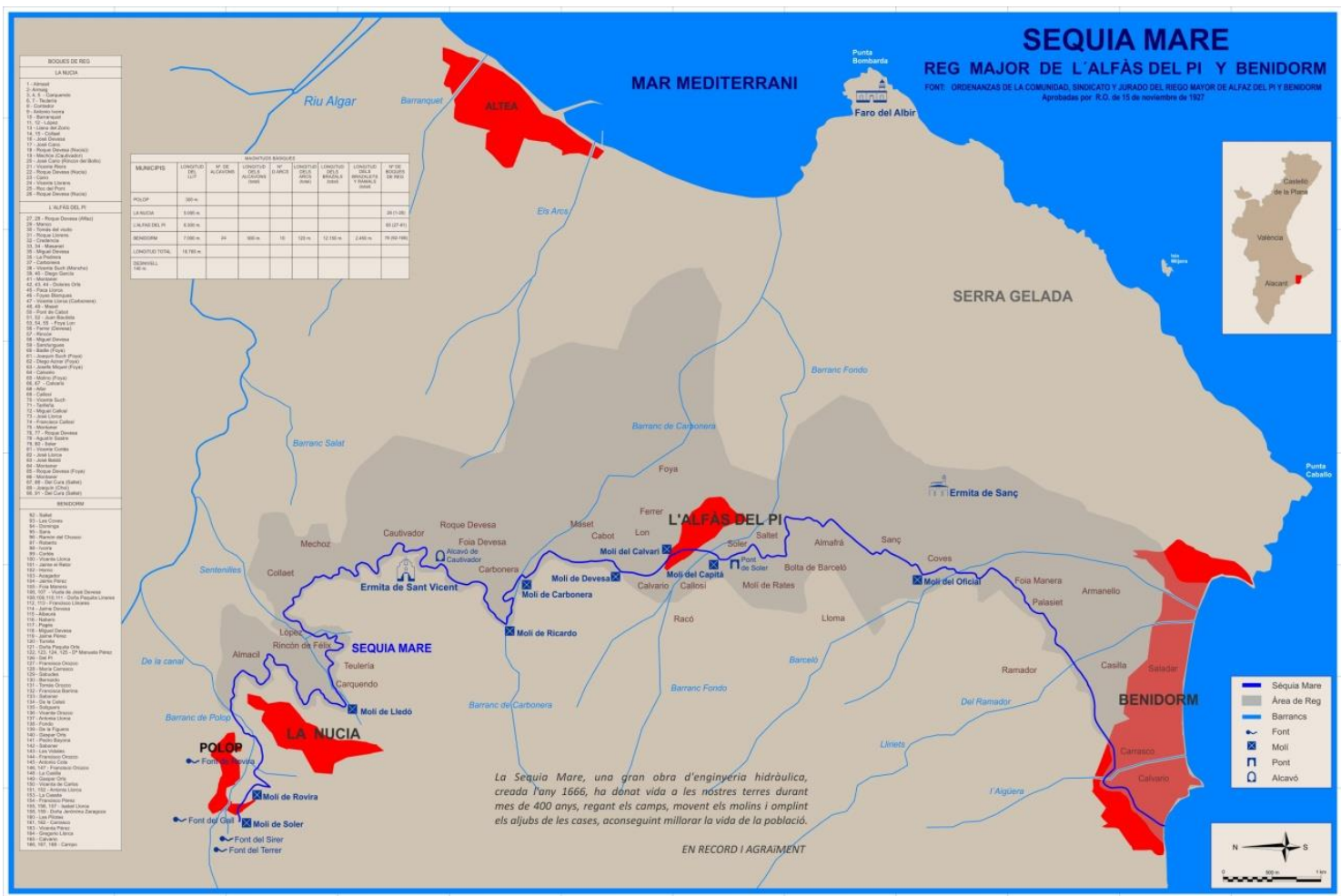

Fig. 1. Panel cerámico conmemorativo ubicado en la ermita de Sant Vicent, en La Nucia, con el recorrido del Reg Major.

La puesta en marcha del riego y la repoblación de Benidorm "despoblada, y sin la población de vasallos, vecinos y moradores, que son menester pasa su buen gobierno y custodia", debido a que no se tenía "huerta y tierras de regadío", son los dos elementos en los que se apoyó Beatriu Fajardo en su plan de revalorización de las tierras de la Baronía. La determinación y el empeño que puso en su ejecución son una prueba en el gran interés que tenía en que el proyecto llegara a término. La principal consecuencia del establecimiento del sistema de regadío fue la revalorización de unas tierras hasta el momento poco pobladas y con una escasa producción agrícola de secano. La documentación de la época indica que el Reg Major permitió la introducción de nuevas producciones, como el tabaco y la dac$s a^{8}$, junto con los cultivos tradicionales de olivo y vid. Al mismo tiempo que aumentaba la productividad de los cultivos, aumentaba la población asentada en el señorío, por lo quese precisaban nuevas infraestructuras. En un documento de 1668, tan sólo dos años después de la implantación del riego, Beatriu Fajardo manifestaba la necesidad de reconstruir las de-

\footnotetext{
7 Carta Pobla de Benidorm de 1666, traslado en castellano de principios del siglo XIX de un texto original en valenciano depositada en el Archivo Municipal de Benidorm. Documento transcrito por F. Amillo (2003, pp. 33-38).

8 F. Amillo (2012, p. 198ss).
} 
fensas de Benidorm, de construir nuevos servicios como un horno y un hostal en Benidorm y La Nucía, así como un molino en Polop que "será muy útil debido al aumento de la población en Benidorm". Estas necesidades son una muestra de la activación económica y social de toda la comarca producida por el riego. Antes de su construcción las rentas eran de 800 libras anuales de alquiler, mientras que en ya en 1668 los ingresos ascendían a 1.300 libras, con unas perspectivas futuras muy halagüeñas ${ }^{10}$. Si se comparan los registros censales el incremento de la población también es bastante significativo, ya que entre los censos de 1646 y 1730 la población de Benidorm pasa de de 50 a 581 personas, un aumento considerable para un territorio prácticamente despoblado hasta el establecimiento del riego. Este proceso de repoblación se fue desarrollando a lo largo de los siglos XVII y XVIII, a medida que se amplían nuevas tierras de cultivo, hasta culminar con la segregación de dos partidas rurales en nuevos municipios: La Nucía en 1705 y l’Alfàs en 1836.

\subsection{La evolución del Reg Major}

Desde finales del siglo XVII y a lo largo de todo el siglo siguiente, con el régimen señorial todavía vigente, se sucedieron las disputas entre regantes y señores por la responsabilidad del mantenimiento del riego. La acequia precisaba de constantes y costosas reparaciones, lo que dio lugar a varios pleitos y convenios que se incumplían constantemente. Un buen ejemplo de estas disputas lo encontramos en la figura de Tomàs Sanç, procurador de los señores de la baronía entre finales del siglo XVII y principios del XVIII. Su misión era la de representar los intereses señoriales frente a los agricultores, por lo que durante el ejercicio de su cargo como procurador fueron recurrentes las acusaciones de actos ilegales y de hacer un uso abusivo de sus prerrogativas en representación de su señora, Josefa de Puigmarín y Fajardo, condesa de Montealegre. Los problemas entre Tomàs Sanç y los vasallos resumen las tensiones constantes entre las dos partes implicadas en el funcionamiento del riego y, en definitiva, las tensiones que en todo el país darán lugar a graves conflictos políticos y sociales durante el siglo XIX.

En 1847 se aprobó un nuevo reglamento para el funcionamiento del riego. A pesar de que el régimen señorial se había abolido diez años antes, este reglamento mantenía elementos feudales propios del régimen anterior, puesto que en el primer artículo del reglamento se especifica que "La acequia principal, con sus brazales, y las aguas del riego mayor del Alfaz, son de la propiedad del dueño de las baronías de Polop y Benidorm, y de sus herederos ó legítimos sucesores" ${ }^{\prime 1}$. Es decir, que la situación para los regantes no había supuesto un gran cambio frente al periodo anterior: la nueva regulación no evita los pleitos por problemas con el agua y por el mantenimiento de las estructuras hidráulicas, lo que genera una gran cantidad de documentación que resulta muy útil para estudiar este periodo histórico ${ }^{12}$.

Los sucesivos propietarios de la acequia no demostraban mucho interés por el riego ysedespreocupaban de su mantenimiento, lo que implicó que el agua se perdiera en el recorrido y no llegara a los regantes. Para solucionar este problema, al amparo de la Ley de Aguas de 1879, se constituyóla Junta de Comunidad de Regantes en 1899, con el fin de aglutinar a

\footnotetext{
${ }^{9}$ Escrito de súplica a la Real Audiencia conservado en el Archivo del Reino de Valencia. Procesos, part. 111, num. 3.499, año 1668. En Orts (1999).

10 F. Amillo (2003, p. 18).

11 Boletín Oficial de la Provincia de Alicante, num. 109, 6-9-1847.

${ }^{12}$ En los antecedentes históricos recogidos en las ordenanzas de 1927 podemos encontrar un resumen de algunos de estos numerosos litigios.
} 
todos los regantes y defender sus intereses de manera adecuada ${ }^{13}$. El siguiente hecho significativo en la historia del riego es la compra por parte de los regantes del dominio directo: por 18.000 pesetas la comunidad de regantes compró la acequia mayor y el molino de Rovira, en el término de Polop. A partir de este momento los regantes consigueron la gestión plena del sistema de riego, terminando con una situación propia del mundo feudal que impedía su correcto funcionamiento. Una vez adquirida la propiedad de la acequia se redactaron unas nuevas ordenanzas en 1927, ordenanzas que actualmente regulan el uso del agua en el Riego Mayor de Alfaz del Pi y Benidorm ${ }^{14}$.

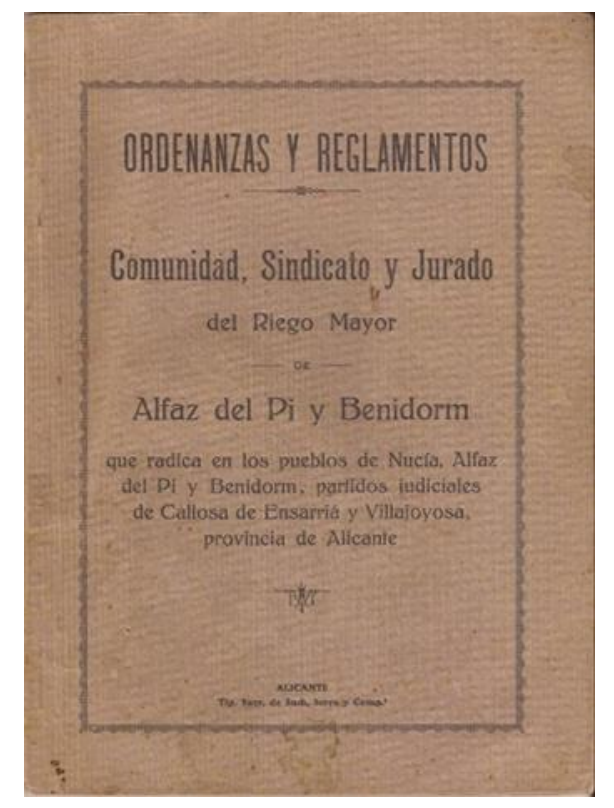

Fig. 2. Portada de las ordenanzas de 1927

En la actualidad el agua de la Séquia Mare llega desde Polop hasta el alcavó del Cautivador, aunque son muy pocos los agricultores que hacen uso de estas aguas y, a partir de este punto, se utiliza el riego por goteo y las aguas del Canal Bajo del Algar. El Reg Major continúa existiendo como una institución privada, si bien subordinada al Canal Bajo del Algar que, a partir de 1940 ha ido desarrollándose en la comarca con el fin de abastecer agua para consumo humano aprovechando las aguas recicladas para riego. El Sindicato del Riego, cuyo actual presidente es Vicente Cano, tiene su sede en La Nucía desde 1995 y en sus instalaciones está depositado el Archivo de la Comunidad de Regantes.

\subsection{El Reg Major en el término municipal de l'Alfäs del Pi}

Según las ordenanzas de 1927 la acequia principal tiene una longitud de 19,05 km desde su nacimiento en el barranco de Polop, a una cota de $177 \mathrm{~m}$ snm, hasta su finalización en

\footnotetext{
13 F. Amillo(2012, p. 222).

${ }^{14}$ Ordenanzas de la Comunidad de Regantes del "Riego Mayor de Alfaz del Pi y Benidorm" que radica en los pueblos de Nucía, Alfaz del Pi y Benidorm, partidos judiciales de Callosa de Ensarriá y Villajoyosa, provincia de Alicante, 1927. Aprobadas en la Real Orden de 15 de noviembre de 1927.
} 
Benidorm. Su longitud real es de $18,78 \mathrm{~km}$., con una superficie de tierras regables de 352 ha. El recorrido de los territorios irrigados por la acequia se divide en tres zonas:

a) La cabecera en el término municipal de Polop (300 $\mathrm{m}$ de acequia)

b) La zona central que comprende los términos de La Nucía $(5.095 \mathrm{~m})$ y l'Alfàs del Pi $(6.300 \mathrm{~m})$

c) El final de la acequia que afecta al municipio de Benidorm hasta llegar al mar $(7.090 \mathrm{~m})$

La estructura principal del Reg Major está formada por una acequia, la denominada séquia mare, y por una sucesión de brazales que llevan el agua hasta las diferentes propiedades. A estos componentes les hemos de sumar una gran cantidad de elementos (galerías, azudes, brazaletes e hijuelas, bocales, lavaderos, aljibes y molinos) que permitían sacar el mayor provecho a unos recursos hídricos siempre escasos.

Acequia principal (séquia mare): cuando se construyó la acequia en el siglo XVII la mayor parte de los canales eran de tierra, sólo algunos tramos estaban construidos con mampostería. Con el paso de los años las acequias se van reforzando con obra, aunque todavía en 1912 la mayor parte del recorrido en Benidorm era de tierra. En la década de 1940 el deterioro de los morteros de cal había provocado que en muchos tramos el agua discurriera por zanjas de tierra, por lo que se ejecutó un proyecto de revestimiento y reconstrucción de los canales. A partir de los años 70 se empieza a reparar la acequia con secciones de hormigón prefabricado y, más recientemente, con tuberías de pvc.

Galerías (alcavons): tramos de la acequia que debían pasar debajo de tierra con el fin de salvar algún accidente geográfico. Las ordenanzas de 1927 registran 24 galerías con una longitud total de $900 \mathrm{~m}$.

Brazales (braçals): tramos de acequia que conducen el agua desde la Séquia Mare a las zonas a irrigar. El propietario de los brazales es la Comunidad de Regantes, mientras que los brazaletes e hijuelas pertenecen a los propietarios de las tierras. En el término de l'Alfàs se han documentado ocho brazales.

Bocales: tomas de agua que se hacían en el tramo de la acequia. Las ordenanzas de 1927 contabilizan un total de 168, de las cuales 65 pertenecen a l'Alfàs del Pi.

Acueductos: estructuras construidas con el fin de salvar los barrancos localizados en el recorrido del riego. En las ordenanzas se citan 10 arcos, de los cuales tres se encuentran en término de l'Alfàs, el de Carbonera, els Arcs y Soler, de los que destaca este último. La construcción de este acueducto responde a la necesidad de salvar el desnivel existente en el barranco Hondo, actualmente en el casco urbano de l'Alfas. Es una obra con una longitud de $15,50 \mathrm{~m}$., realizada con mampostería trabada con mortero y revestida también con un mortero de cal. Tiene una doble arcada de una altura máxima de 5,85 m. con un contrafuerte en cada cara de la estructura. 


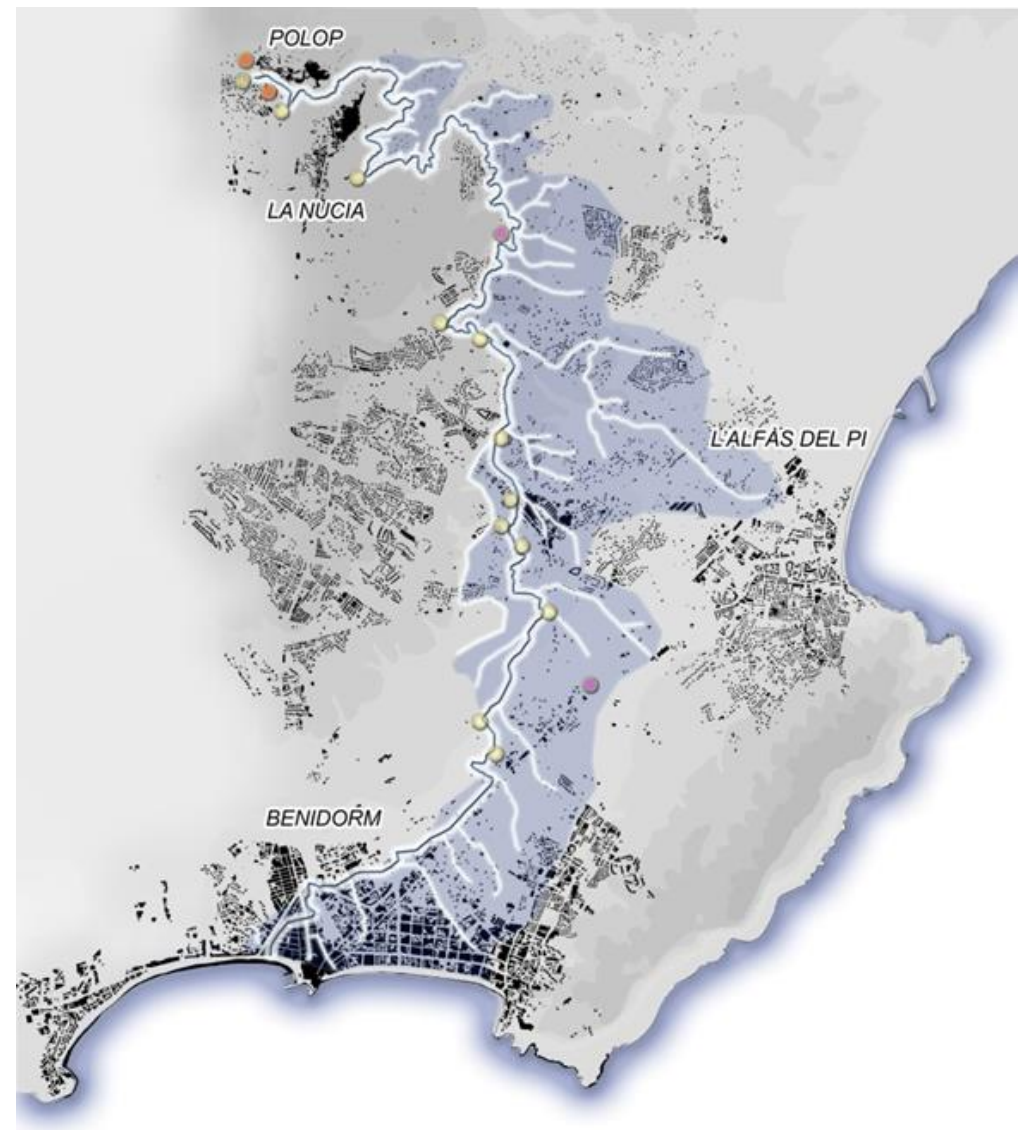

Fig. 3. Recorrido completo del Reg Major.

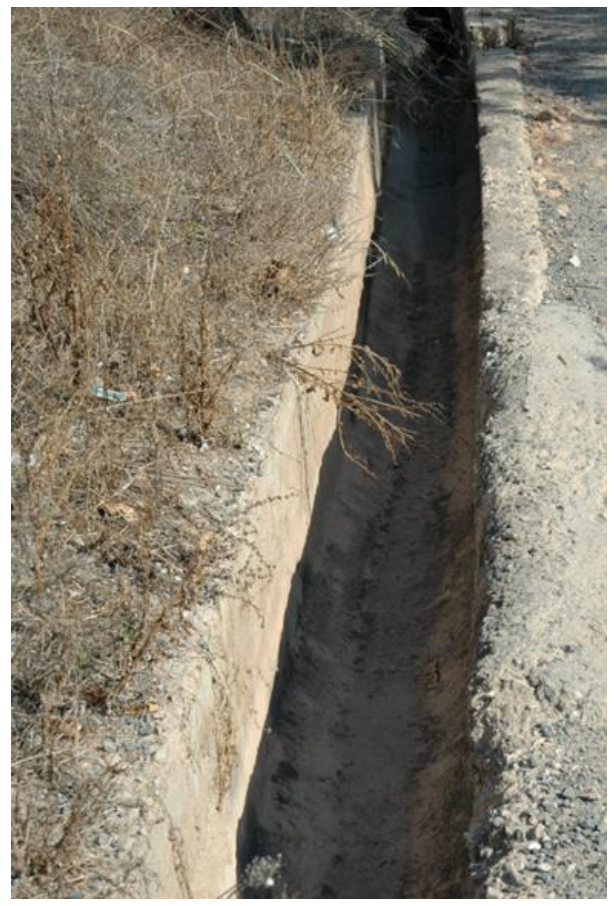

Fig. 4. Tramo de sèquia mare en la partida de Carbonera (l'Alfàs del Pi). 


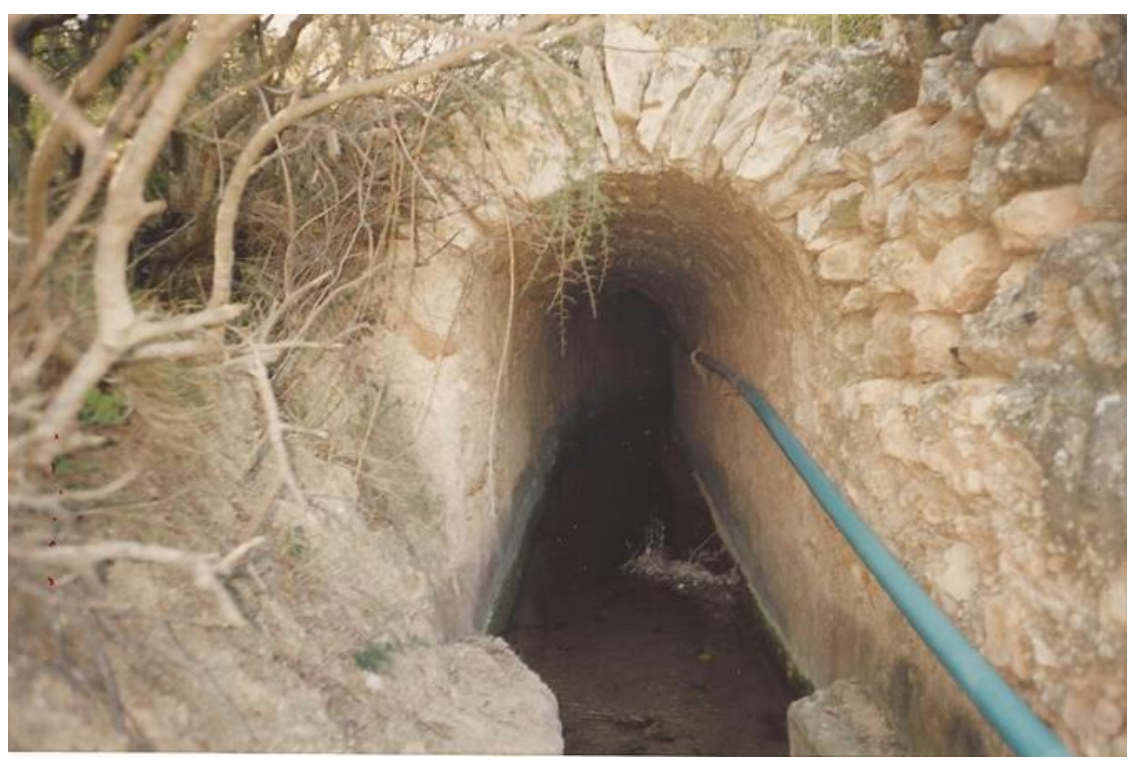

Fig. 5. Alcavó situado en la partida del Captivador (La Nucía).

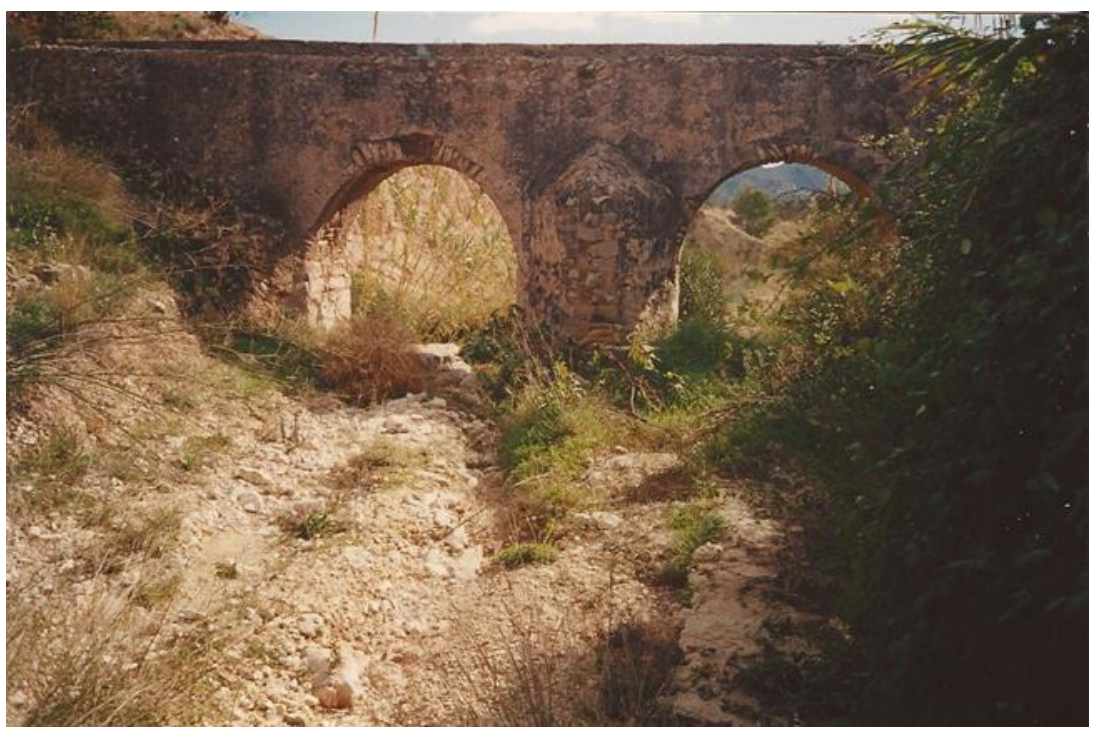

Fig. 6. Acueducto de Soler (l'Alfàs del Pi).

Molinos: junto al cauce principal de la acequia se instalaron molinos que permitían aprovechar la fuerza del agua para diferentes usos. La mayoría de ellos eran molinos harineros, aunque el molino de l'Almarx en La Nucía se empleó también para producir energía eléctrica. En 1927 se contabilizan 9 molinos en el Reg Major, 5 de ellos localizados en l'Alfàs, al que hemos de añadir el Molí de Rates que no aparece en la relación de 1927 porque ya no estaba en funcionamiento. Estos molinos harineros fueron de gran importancia en la economía de la comarca hasta mediados del siglo XX y son el testimonio de una cultura agraria y de unas formas de vida que actualmente han desaparecido. Desde una perspectiva patrimonial los molinos del Reg Major son muy interesantes, ya que algunos de ellos todavía conservan sus partes más significativas, como el cup y el cacau. La gestión de los molinos 
ha proporcionado mucha documentación, ya que al aportar numerosas rentas a los señores estaban sujetos a un gran control fiscal. Por lo general, los propietarios de los molinos eran absentistas y arrendaban su uso a cambio de una renta. Estos mismos arrendatarios, a su vez, podían subarrendar las labores de molienda y de cuidado del molino, con lo que resulta complicado localizar a las familias que realmente trabajaron en los molinos.De norte a sur, los molinos hidráulicos del Reg Major en término de l'Alfàs son Molí de Barró, Mànec, Devesa, Calvari, Capità y Rates.

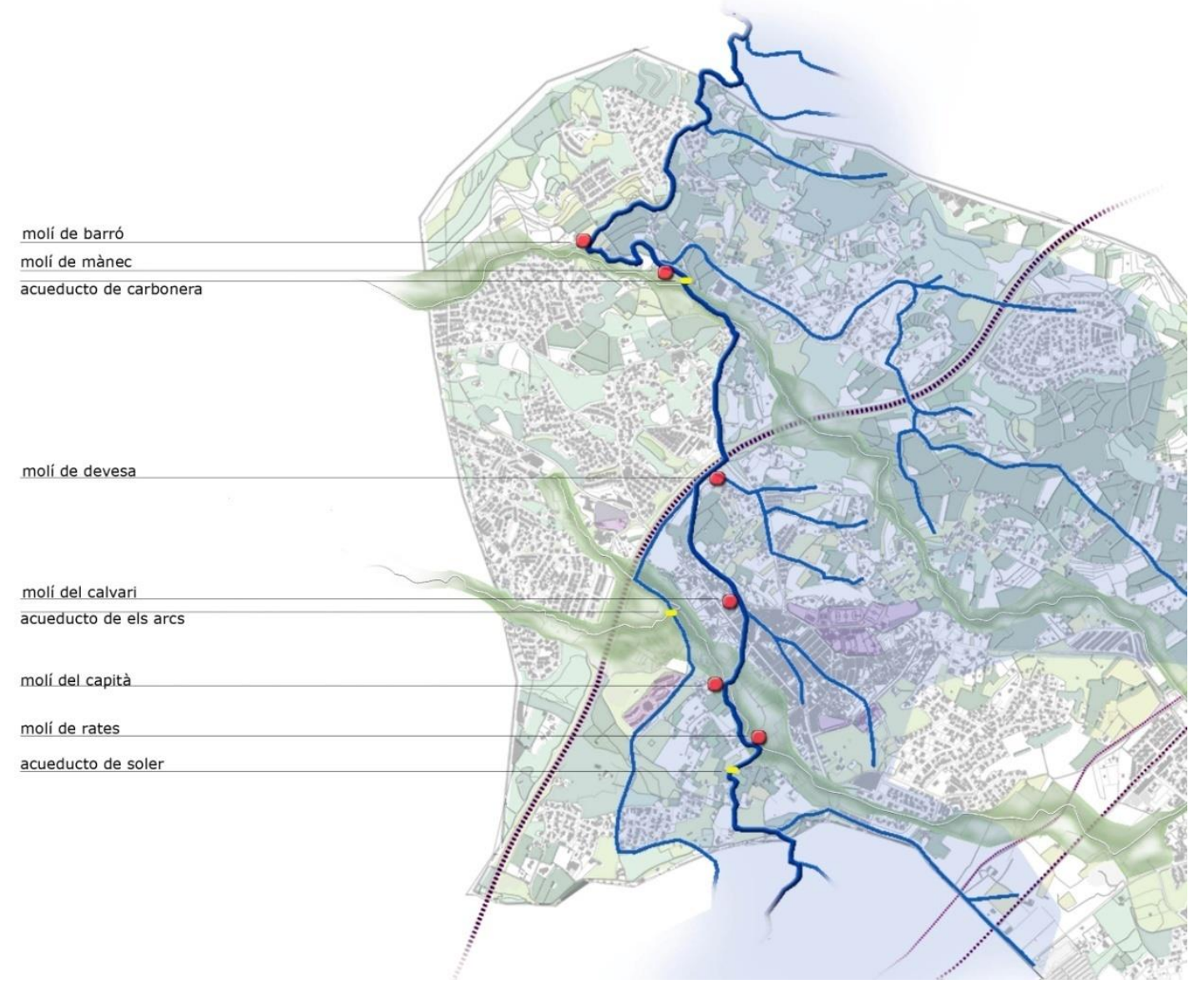

Fig. 7. Ubicación de los molinos y acueductos en el t.m. de l'Alfàs del Pi.

\section{La intervención}

Los objetivos propuestos en el proyecto de puesta en valor del Reg Major son:

- Conocer y proteger unos bienes patrimoniales en riesgo de desaparecer.

- Conservar de manera adecuada los elementos inmuebles que conformar el sistema de riego.

- Poner en relación el patrimonio cultural con su entorno territorial

- Difundir de manera didáctica los valores paisajísticos, naturales y culturales del Reg Major.

- Diseñar un eje cultural que articule el municipio de l'Alfàs del Pi desde el interior hasta la costa. 
- Crear un producto turístico sostenible.

- Fomentar el desarrollo de actividades económicas de carácter turístico y cultural que contribuyan a la generación de empleo.

- Potenciar el respeto por el patrimonio cultural y por un uso responsable del agua

Para ello, se plantea actuar mediante las siguientes estrategias:

- Protegiendo jurídicamente los elementos del Reg Major.

- Implicando en el proyecto a los regantes, a los propietarios de los terrenos y a las administraciones públicas.

- Investigando y catalogando los bienes que conforman el riego, tanto culturales como naturales.

- Conservando e interviniendo en aquellos bienes inmuebles que precisen de una actuación arquitectónica.

- Actuando en los cauces de los barrancos con el fin de llevar a cabo su regeneración paisajística.

- Llevando a cabo un proyecto de interpretación del patrimonio que difunda de manera didáctica sus valores.

- Teniendo presente en la fase de diseño y ejecución del proyecto los criterios de accesibilidad física e intelectual al patrimonio natural y cultural.

- Realizando un plan de promoción para dar a conocer el producto turístico.

Desde una perspectiva urbanística el conjunto del Reg Major se ha propuesto declararlo como Bien de Relevancia Local, en la categoría de Espacio Etnológico de Interés Local, dentro del Catálogo de Bienes y Espacios Protegidos del Plan General de Ordenación Urbana que se está elaborando actualmente. Además, a los cuatro molinos y los tres acueductos se les dota de una figura de protección como BRL de manera individualizada.

Los trabajos de conservación se centrarán, en primer lugar, en la rehabilitación del Molí de Mànec, con el fin de crear el Centro de Interpretación del Reg Major de l'Alfàs. El Molí de Mànec es un molino harinero situado en la orilla izquierda del barranco de Carbonera. Es un inmueble de propiedad municipal y se encuentra enclavado en una de las zonas del barranco que posee mayor interés paisajístico. La actuación en el molino tiene como objetivo restaurar su estructura, evitar su ruina definitiva y habilitarlo como un área expositiva. La intervención arquitectónica afectará también a los acueductos que cruzan los barrancos y a la acequia principal, identificando los tramos en uso, registrando las reformas llevadas a cabo a lo largo del funcionamiento del riego y recuperando los tramos deteriorados.

La creación de la senda será una actuación respetuosa con la naturaleza de los cauces, tratando de minimizar el impacto en el entorno. La senda se adaptará a la línea de dominio público con un desarrollo de pendientes suaves para conseguir la máxima accesibilidad posible. Se emplearán materiales que permitan la integración de los equipamientos y sistemas de seguridad, que resistan al vandalismo y cuya reposición sea lo más económica posible. Con el fin de facilitar el uso de la senda y de dotarla de la certificación de calidad y seguridad adecuada, se podrá solicitar la homologación de la ruta a la Federació d'Esports de Muntanya i Escalada de la Comunitat Valenciana dentro de la categoría de Sendero Local.

Los barrancos de Carbonera, Hondo y Soler desembocan en la playa de l'Albir. Sus cauces en la actualidad son espacios residuales y, puesto que gran parte del desarrollo urbanístico del municipio queda próximo a estas líneas de cauce, se tiene previsto su puesta en valor como ejes vertebradores del territorio, conectando espacios naturales con otros ámbitos de 
valor cultural, ambiental y paisajístico. Por tanto, se prevé transformar los barrancos en ejes que conecten la zona norte del municipio (Reg Major), con el casco urbano (Centro Etnológico Municipal y centro histórico) y la zona litoral de l'Albir (Villa Romana y Parc Natural de la Serra Gelada).

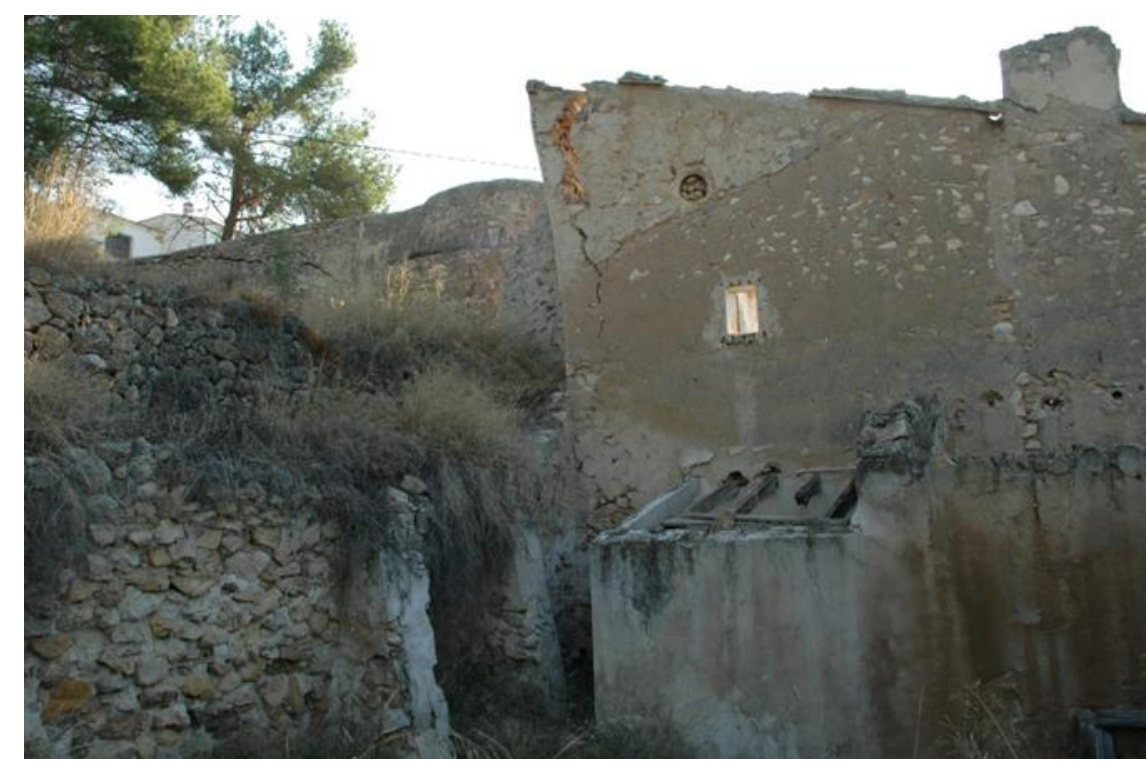

Fig. 8. Fachada occidental del molí de Mànec.

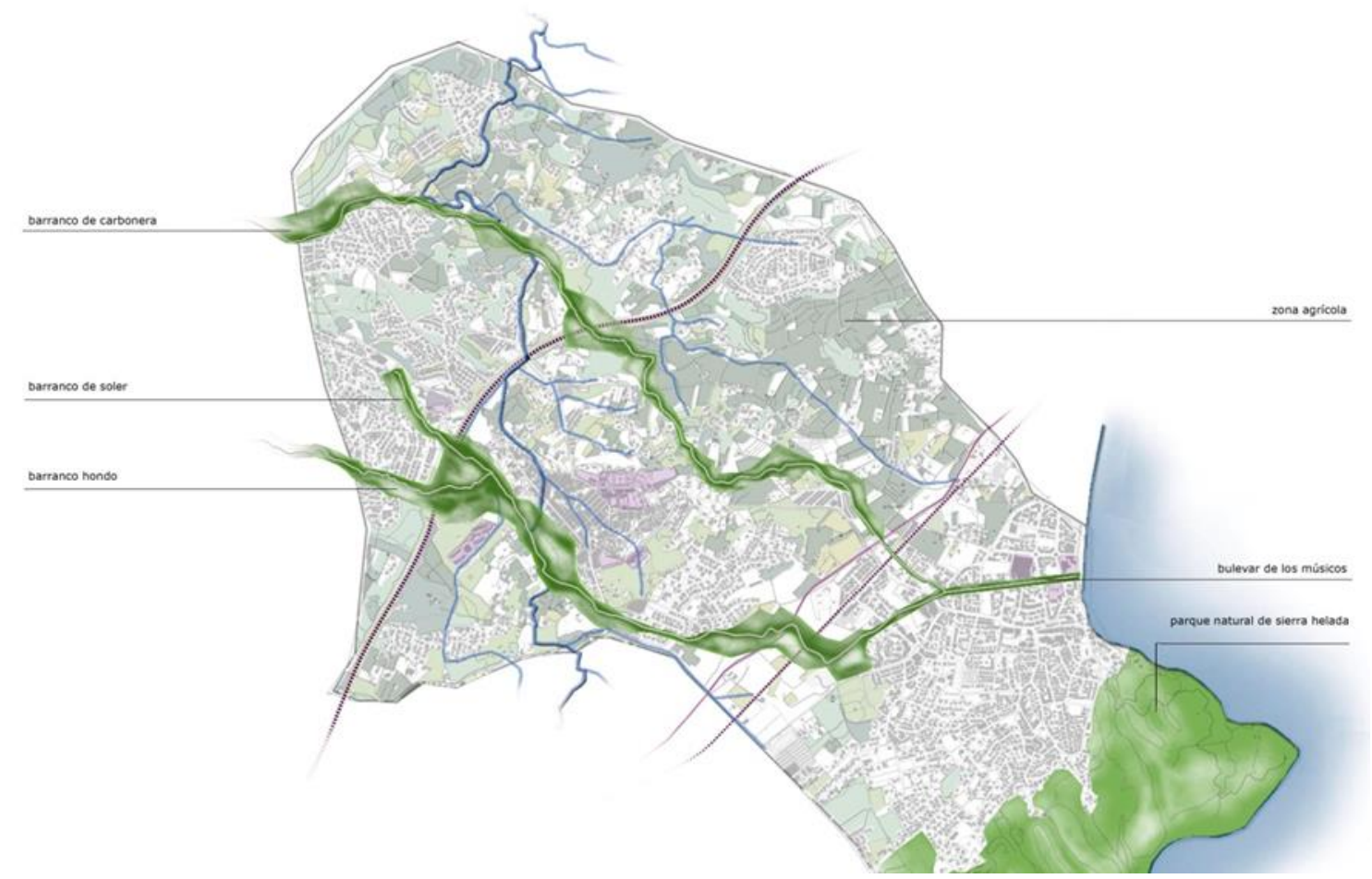

Fig. 9. Conexión de los corredores verdes. 
El eje narrativo principal previsto es el aprovechamiento del agua como motor de desarrollo económico, social y cultural. El establecimiento del Reg Major posibilitó el asentamiento y desarrollo unas poblaciones que deben su presente a estas infraestructuras hidráulicas y a las personas que las crearon y utilizaron en los últimos 350 años. Queremos comunicar que la escasez del agua en nuestro territorio es un hecho constante a lo largo de los siglos, que el agua es el recurso que hace posible la vida y el desarrollo de las sociedades humanas, por eso su aprovechamiento y gestión es una necesidad que nos comunica de forma directa con el pasado. El agua es el protagonista del planteamiento expositivo, un elemento muy presente en la vida actual que hará de nexo de unión entre los hechos históricos y las experiencias cotidianas de los visitantes.

A partir de la línea narrativa básica se desarrollan otros ejes temáticos que articularán el recorrido, como son:

- El funcionamiento del riego desde una perspectiva técnica.

- La complejidad en la gestión del agua desde la creación del riego hasta la actualidad.

- El cambio de un modelo feudal de propiedad de la tierra y del agua a un sistema en que los regantes gestionan sus necesidades.

- Transformación de l'Alfàs del Pi de una comunidad agrícola a una ciudad turística y de servicios.

- Las obras de ingeniería hidráulica en época moderna.

- La importancia de los molinos en la economía local: los cambios en la alimentación.

- Topografía histórica de l'Alfàs del Pi y la comarca de la Marina Baixa (siglos XVII$\mathrm{XX})$.

- Toponimia: el nombre de las personas, de los lugares y de los artefactos hidráulicos

El trazado de la Séquia Mare en el término de l'Alfàs del Pi tiene una longitud de 6,3 km. desde su inicio en la partida del Captivador hasta su final en la partida de Soler, junto al linde con Benidorm. Se identifican dos áreas: la zona septentrional del riego, en el barranco de Carbonera, y la zona meridional, en el casco urbano de l'Alfàs y el barranco de Soler. La articulación entre ambas zonas se realiza a partir de los conectores verdes que ponen en contacto las dos zonas entre sí y cada una de ellas con el resto de espacios de interés cultural y medioambiental que posee el municipio. 
Zona 1. Barranco de Carbonera. Es el espacio donde mejor se muestran los valores paisajísticos del Reg Major, ya que esta zona tiene una baja densidad de urbanización. Esta zona se plantea como el inicio de la ruta, con el Molí de Mànec como sede del Centro de Interpretación del Reg Major de l'Alfàs.

Tabla 1. Elementos de la Zona 1
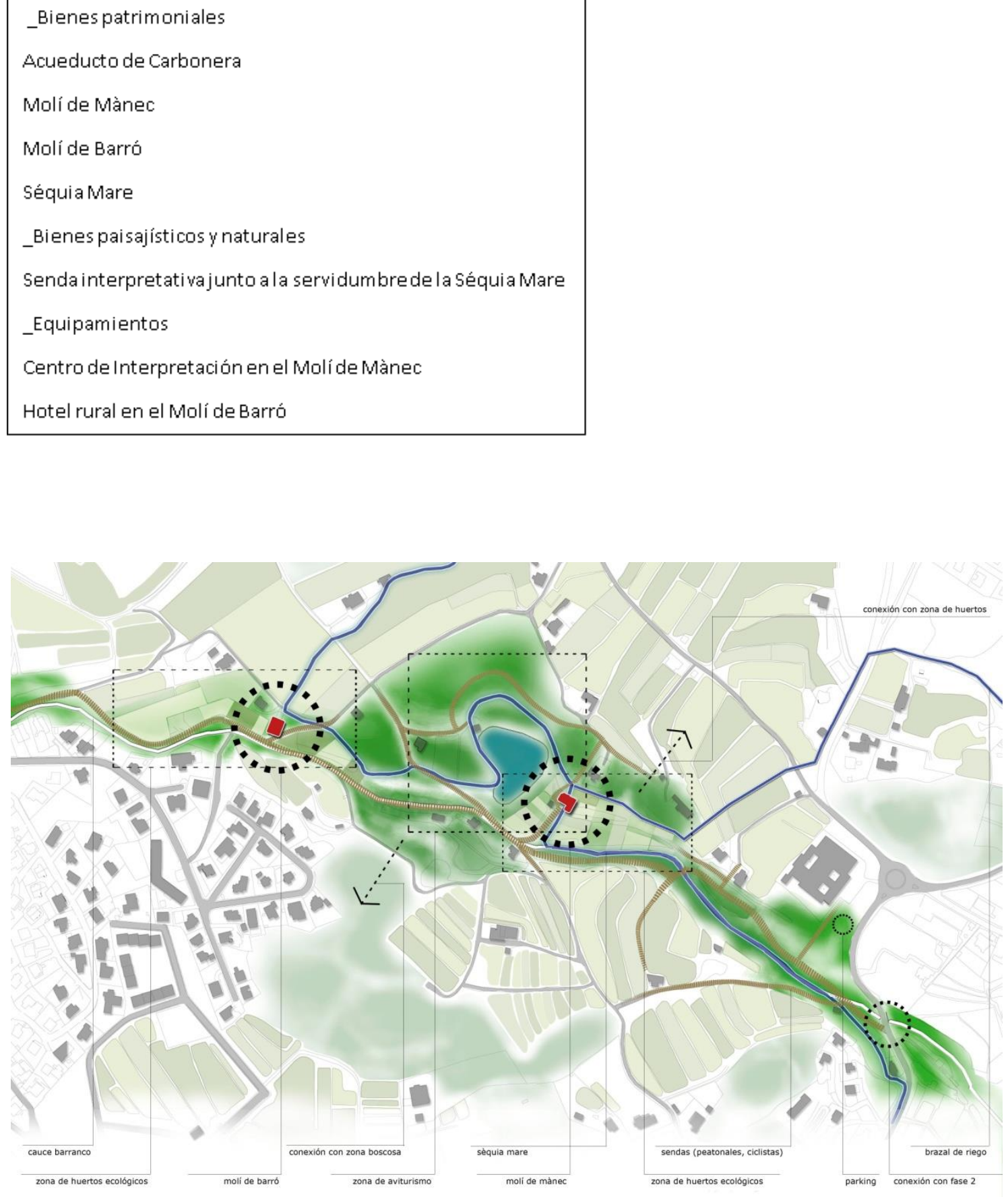

Fig. 10. Equipamientos y recursos de la Zona 1 
Zona 2. Casco urbano y barranco de Soler. La avenida de Carbonera es un camino histórico que comunica el casco urbano de l'Alfàs con la partida del Captivador y tiene un trazado paralelo al de la séquia mare. Este vial se puede emplear para comunicar la Zona 1 con la 2 , cuyos elementos más significativos se encuentran en el casco urbano de l'Alfàs del Pi. La Zona 2 iniciaría su recorrido en el Centro Etnológico Municipal, continuando por un itinerario específico tematizado desde el Molí de Rates, pasando por el acueducto de Soler hasta llegar al acueducto de els Arcs. Esta zona, donde finaliza el recorrido del Reg Major, conecta con la oferta cultural del casco urbano de l'Alfàs y con la playa de l'Albir.

Tabla 2. Elementos de la Zona 2
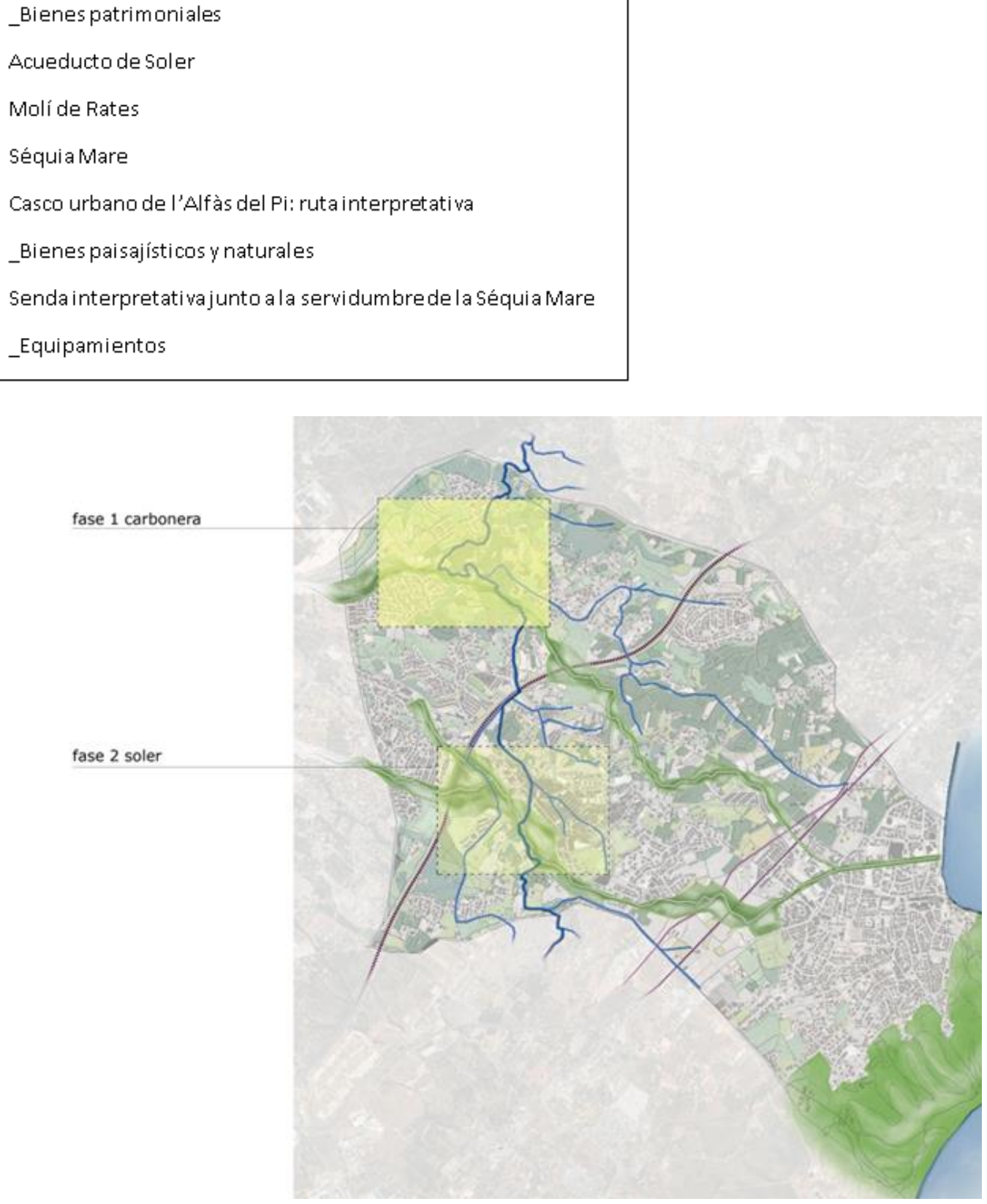

Fig. 11. Localización de las áreas de actuación 
La intervención en el Molí de Mànec tiene como objetivo habilitar esta estructura como un centro de interpretación con una doble función: área expositiva y centro de recepción de visitantes. Como espacio expositivo el proyecto museográfico integrará las tres dimensiones del recurso: paisaje, cultura y medioambiente, tomando como elemento articulador el agua y sus formas de aprovechamiento. Se trasmitirá la importancia de los molinos harineros para la economía local y se contextualizarán el resto de artefactos hidráulicos que conforman el riego. El centro de interpretación constituye en elemento central del proyecto interpretativo y punto de partida de la oferta patrimonial. Es el lugar donde se expondrán paneles, objetos y relatos orales relacionados con la cultura del agua y con los métodos empleados para regar los cultivos, haciendo hincapié en la contemporaneidad de estos elementos históricos. Se desarrollaran también las actividades didácticas vinculadas al programa de difusión. Como punto de recepción debe cumplir las tareas de información relacionadas con el parque cultural, orientando a los visitantes de los servicios existentes, del programa de actividades, normativa y buenos usos medioambientales.

La ruta irá apoyada con paneles tradicionales, publicaciones en papel y aplicaciones como la realidad aumentada o Layar como medios interpretativos.

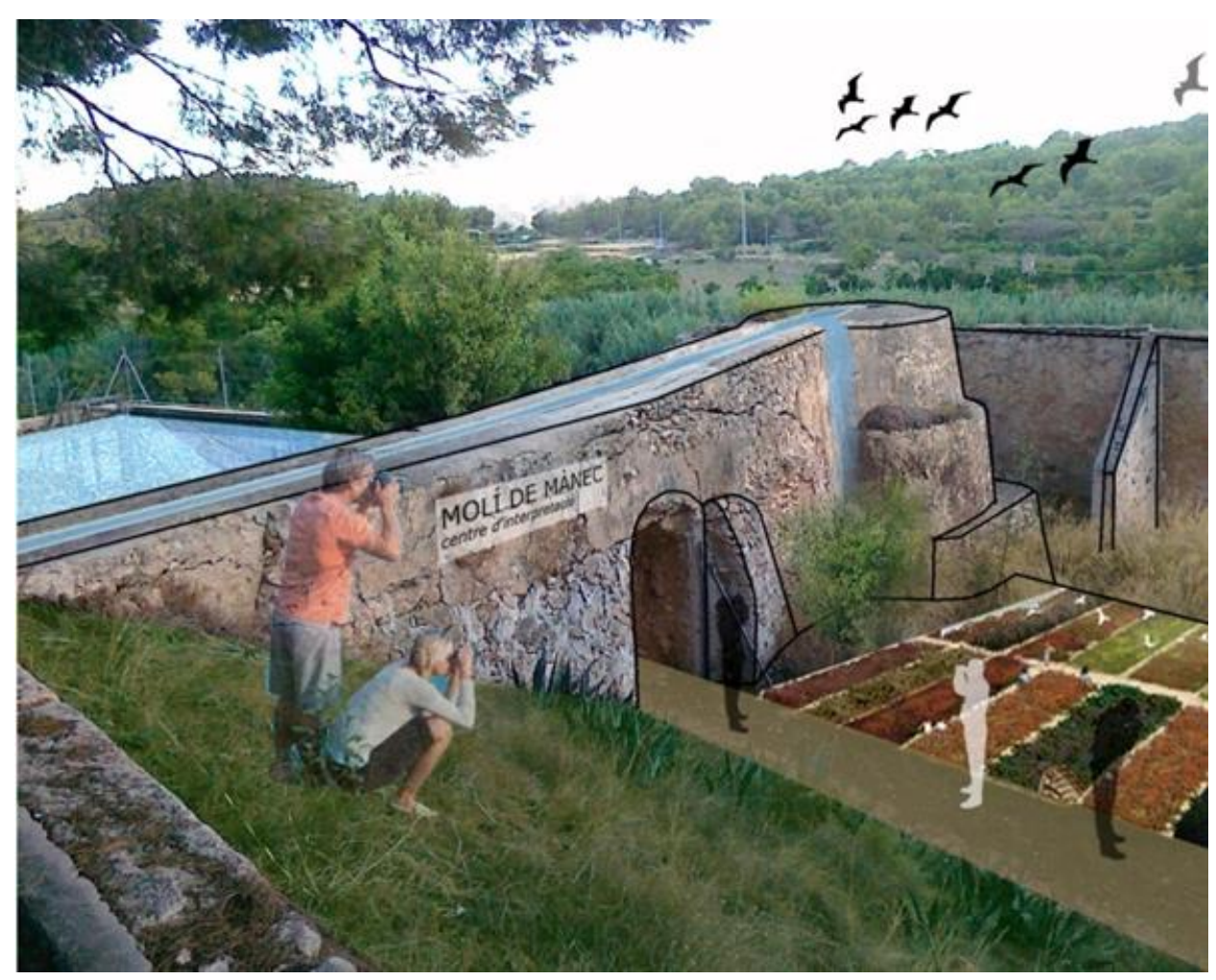

Fig. 12. Recreación del espacio interpretativo del molí de Mànec.

Se proponeun itinerario interpretativo autoguiado mediante diferentes medios, ya que el hecho de que el visitante sea autónomo permiteel acceso en cualquier momento. Este sistema tiene la desventaja de que de un mantenimiento constante debido a posibles actos vandálicos o al desgaste por el uso. En ocasiones puntuales para grupos concertados o actividades concretas se programarán visitas guiadas, interpretadas o teatralizadas

La valorización turística del Reg Major deberá realizarse a partir de un diagnóstico inicial que establezca el contexto social, las estrategias territoriales y análisis de la demanda, al 
tiempo que compruebe la relación entre las demandas percibidas y la oferta y modos de divulgación existentes. A partir del análisis de las necesidades e intereses detectados, se tendrán en cuenta los siguientes conceptos para desarrollar el plan de promoción:

- Calidad del producto: proyecto museográfico innovador y atractivo y ejecución correcta del plan de mantenimiento.

- Sostenibilidad: tratar de romper la estacionalidad de las visitas turísticas.

- Integración del producto en políticas territoriales que superen el ámbito municipal

- Identificación del producto con una marca de calidad.

- Planificación de todas las actividades de divulgación.

- Ampliar al máximo los grupos de potenciales visitantes.

\section{Conclusión}

La necesidad de incluir proyectos de puesta en valor del patrimonio cultural y natural dentro de las estrategias de desarrollo local de un municipio cada vez es más evidente. Esta concepción social del patrimonio, en la que los bienes patrimoniales dejan de ser recursos para convertirse en productos turísticos, es la que convierte al patrimonio en un motor de desarrollo económico. El proyecto de recuperación del Reg Major de l'Alfàs es una actuación transversal que implica a diferentes sectores económicos. Abre la posibilidad de equilibrar la oferta turística del municipio, conectando los recursos de la playa con el casco urbano y el interior del término municipal. Se trata de una actuación viable y sostenible que responde a la necesidad de salvaguardar los valores materiales e inmateriales de un municipio que ha perdido casi por completo su identidad como comunidad agrícola. Después de los 350 años trascurridos desde la construcción del sistema de riego la agricultura ha sido sustituida por el turismo como principal motor económico de la comarca. Los molinos harineros han dejado de funcionar, algunos han desaparecido, otros se han reconvertido en viviendas y unos pocos mantienen a duras penas su estructura y maquinaria. El agua de la séquia mare ha dejado de regar muchas de las tierras a las que llegaba antiguamente y los lavaderos y aljibes han perdido su razón de ser. Sin embargo, el Reg Major es un bien cultural todavía vivo y da forma a un paisaje histórico que debemos proteger, conservar y difundir con el fin de preservar la memoria de las personas que durante tres siglos aprovecharon sus aguas e hicieron posible el desarrollo económico y social de la Marina Baixa.

\section{Referencias}

Alemany, R., et alii (1988): Carta de poblament de Benidorm, Benidorm.

Amillo, F. (1999): "Beatriu Fajardo de Mendoza y la segunda fundación de Benidorm”, Revista de Festes Majors Patronals, pp. 127-130.

Amillo, F. (2001): "La carta de poblament de Benidorm de 1666 atorgada per Beatriu Fajardo de Mendoza", Revista de Festes Majors Patronals

Amillo, F. (2003): Beatriu Fajardo de Mendoza y la carta puebla de Benidorm (1666), Benidorm. Amillo, F. (2005): “Tomàs Sanç i l'ermita de Sanç”, Revista de Festes de Sant Antoni, pp. 5154. 
Amillo, F. (2007): "El Reg Major de l'Alfàs", en Espinosa, A. y García, J.L. (eds), Actes de les II Jornades de Patrimoni Natural i Cultural de la Marina Baixa. Patrimoni, aigua i clima a la Marina Baixa (La Vila Joiosa, 17-18 de desembre de 2005), La Vila Joiosa, pp. 29-38.

Amillo, F. (2012): Historia de Benidorm, de los orígenes a 1960, Benidorm.

Fuster, J. (1991): Baronía de Polop, Polop de la Marina.

Frías, J.R.(2003): En busca de los riegos casi perdidos. Breves apuntes sobre la Séquia Mare en las partidas del Cautivador de la La Nucía y l'Alfàs del Pi, Festes del Segon Centenari de l'ermita deSant Vicent del Captivador (1803-2003), La Nucía.

Frías, J.R. (2008): "La Séquia Mare. Un patrimonio arquitectónico e hidráulico digno de protección”, Revista de Fiestas Patronales, l’Alfàs del Pi, pp. 109-113.

Galiana, A. (2009): L'extrem sud de la Marina: recuperació de la toponimia antiga, Sarrià, 3: 6-23.

Galiana, A. (2011a): Documentació histórica i bibliográfica de la Marina Baixa, CD-Rom, la Vila Joiosa.

Galiana, A. (2011b): "La fundació de Vilajoiosa per Bernat de Sarrià", Sarrià, 6: 4-39.

Glick, T., Guinot, E, Martínez, L.P. (eds) (2000): Els molins hidràulics valencians. Tecnologia, història $i$ context social, 2000.

Orts i Bosch, P.M. (1976): La carta de poblament de Benidorm i el almirall Bernat de Sarrià, Valencia.

Orts i Bosch, P.M. (1999): "Beatriu Fajardo de Mendoza o Beatriu Fajardo de Guzmán", Revista de Festes Majors Patronals, Benidorm, pp. 125-126,

Orts i Bosch, P.M. (2003): "Els Fajardo i les seues aliances matrimonials", Revista de Festes Majors Patronals, Benidorm, pp. 182-184.

Orts i Bosch, P.M.(2006a): "La carta pobla de Benidorm (1325)", en Per la memoria històrica dels valencians, Valencia, pp. 225-234.

Orts i Bosch, P.M. (2006b): "Bernat de Sarrià, primer senyor territorial de Benidorm (13251336), en Per la memoria histórica dels valencians, Valencia, pp. 235-246.

Orts i Bosch, P.M. (2006c): "Introducció a la història de la Vila Joiosa", en Per la memoria històrica dels valencians, Valencia, pp. 325-350.

Torres, F. (2013): L'Alfàs. Dos-cents anys (1812-2012), l'Alfàs del Pi.

Yáñez, A. (2000): Historia y descripción de Benidorm, Alicante. 